\title{
Habla su biblioteca \\ El Estado renacentista (II): El arte dello stato en la filología románica
}

Katherine Miller

Directora de Asuntos Culturales Biblioteca "Florentino Idoate, S. J."

Universidad Centroamericana"José Simeón Cañas"

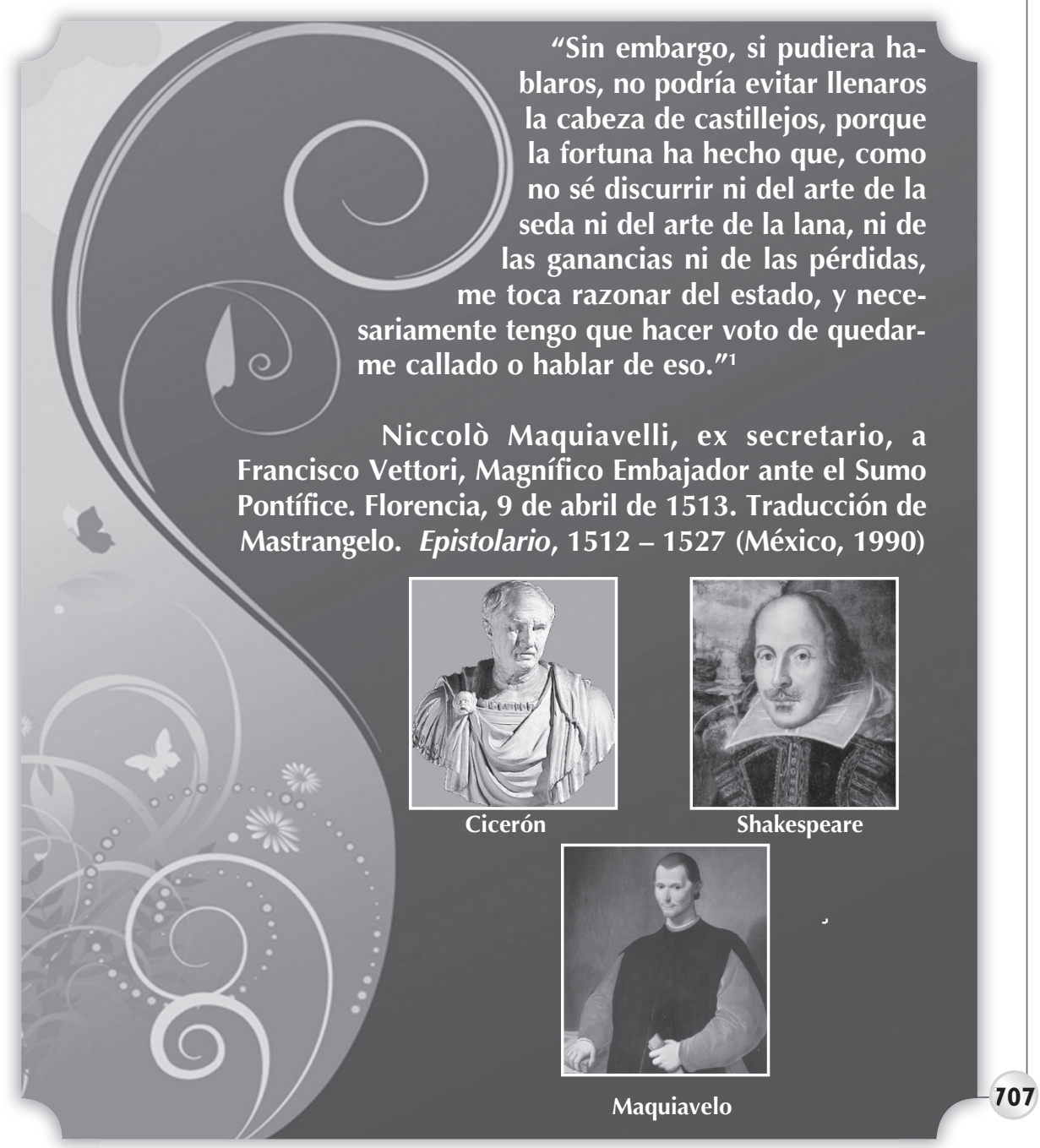


En su carta citada líneas arriba, el gran Maquiavelo explica a su amigo, Vettori, el Magnífico Embajador ante el Sumo Pontífice, que rechazará la discusión, estudio y argumentación [ragionare] del comercio para dedicarse a la discusión, estudio y argumentación [ragionare] sobre la cuestión del estado.

Nosotros en el siglo XXI podemos $-\mathrm{y}$ debemos - preguntar: ¿Qué, exactamente, es lo que Maquiavelo declara que estará estudiando [ragionare] cuando menciona que razonará sobre el estado, "ragionare dello stato"?

Propongo también que deberíamos preguntarnos lo siguiente: si bien es cierto que las palabras y conceptos cambian sus significados a través de los siglos, además de cambiar sus significados en distintas situaciones históricas, ¿sería el caso que el discurso político renacentista sobre las dimensiones del concepto del estado es lo mismo que el discurso político moderno sobre el concepto del estado?

Mi argumento sería que los conceptos renacentistas y modernos no representan el mismo significado que las formas vernáculas del término latín, status, en el siglo $\mathrm{XVI}$, cuando escribió Maquiavelo. Además, propongo que no debemos limitarnos a examinar este concepto solamente en su aspecto filológico, partiendo de la mera decisión de como traducir en cualquier idioma vernáculo del período y con cuál palabra traducir el término status. Sería de investigar los cambios en el entendimiento del fenómeno y concepto del estado a través de los siglos.

En fin, nos conviene, mejor, investigar la naturaleza de la actividad que Maquiavelo se propone estudiar, analizar, discutir e investigar [ragionare] acerca del estado en lugar de estudiar, analizar, discutir e investigar [ragionare] acerca de asuntos comerciales como la compra y venta de la seda y de la lana o las ganancias y pérdidas en el comercio. Declara en su carta su intención de ragionare dello stato.

Ahora, los pensadores políticos del humanismo cívico de Florencia comentaron-todos ellos con sus ojos enfocados fuerte y completamente en la Roma de sus ancestros tal como se lo habían encomendado los pensadores de su península desde Dante y Petrarca hasta Maquiavelo y más allá- sobre qué clase de república sería el gobierno más propicio para su querida Florencia. Sus obras no son escritas en bibliotecas aisladas sino diseñados para servir como instrumentos políticos, con el objetivo de influenciar el funcionamiento de su gobierno aquí en esta tierra en el diario vivir.

Esta idea fue visualizada en Florencia del cinquecento en frescos pintados en las paredes de los edificios en Florencia y en ilumina- 
ciones en los manuscritos en que escribieron sus elogios y consejos a su ciudad-estado-república. Consideramos, por un momento, uno de estos manuscritos iluminados en que veamos Leonardo Bruni, parado y apoyando su libro abierto. Desde el libro salen rayos color de oro como que son del sol que se dirigen hacia una representación, en la misma iluminación, de las torres en la ciudad de su querida República de Florencia. El mensaje es que Ser Leonardo Bruni desea, por medio de sus escritos, influenciar los actos cívicos del pueblo y del gobierno del que él es Canciller.

Que los escritos de los humanistas del cinquecento sobre el estado-ciudad-republica impactaron la vida real del gobierno, no se puede dudar. Sus escritos no eran simples facturas para correos electrónicas de que los contenidos han desparecido hace tiempo y para siempre. Tomemos un ejemplo más para no alargar la lista. Es de Lorenzo Valla, humanista y filólogo quien comprobó por escrito - y causó, como resultado, actividades vengativas feroces por parte del Vaticano en la vida real- que la Donación de Constantino era una fraude y que, por lo tanto, el Papado no tenía derecho a la propiedad y poder de los Estados Papales porque el documento en que esta donación fraudulenta se basó había sido escrito por unos monjes de aproximadamente el siglo VIII, quienes falsificaron el contenido del documento que Valla comprobó, por los artes de la filología y el examen gramático, que no era de los tiempos de Constantino el Grande (siglo IV), sino de unos cuatro siglos después. (Véase The Treatise of Lorenzo Valla on the Donation of Constantine, Ed. C.B. Coleman (Toronto, 2005). Solamente podemos imaginar los efectos de esta incursión de la filología en la vida real de la política.

Como hemos visto en la carta de Maquiavelo a Vettori en 1513, citado al principio, había una cierta tensión entre la práctica del comercio y la práctica del arte dello stato. Propongo considerar que es que Maquiavelo estaba estudiando y cuales conceptos del estado estaban au courant en la Europa de la Modernidad Temprano, la descripción actual del período que antes fue denominado El Renacimiento - aunque en realidad, eran Renacimientos (en plural). Ahora bien, es cierto que el término Modernidad Temprana suele anunciar la pre-figuración de fenómenos que se realizan, teleológicamente, como por arte de la imaginación en el período Moderno, talvez un poco antes, durante y después de la revolución de las luces, la llustración europea. Pero una breve examinación filológica de la palabra stato, y la realidad de su funcionamiento, siguiendo el ejemplo siempre de Roma, nos iluminaría el fatum del término status, el estado, the state, lo stato, en su metamorfosis desde la Modernidad Temprano a tra- 


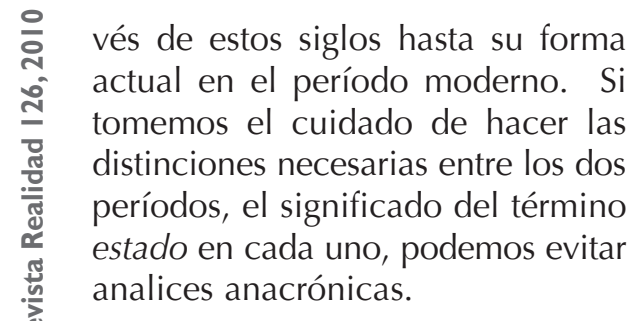

Pero comenzamos con una definición moderna de la palabra y concepto en latín de status, de lo que desprenden los términos en los vernáculos, stato, l'état, staat, state, estado, etc. Este ejercicio nos ayudaría esclarecer lo que no es una definición que nos servirá en la examinación de estos textos de la Modernidad Temprano comenzando en el siglo XV. Es que el concepto del estado es demasiado importante en el análisis y comprensión de textos políticos renacentistas para dejarlo a comentadores que ocupan definiciones equivocados y sobrepuestos derivados de pensadores muchos mucho más tardes, después, en los siglos XIX hasta XXI.

En la visión moderna, entonces, el estado es descrito como una comunidad política organizada bajo un gobierno que goza de un monopolio del uso legítimo de la fuerza dentro de un territorio geográfico específicamente definido y que no es súbdito a otro estado; es decir, es soberano. Aunque hay estados que no son soberanos. (Véase la etimología histórica de la palabra state en el Oxford English Dictionary, Vol. 16 (1989).
Sería mi contención que la definición moderna del término y fenómeno histórico, estado es un concepto eminentemente distinto del concepto renacentista del estado. Después del siglo XVII, Thomas Hobbes lo define como un estado moderno, abstracto e impersonal separable de la comunidad sobre que mantiene soberanía y que trasciende los individuos quienes lo componen o quienes reinan sobre el estado en cuestión. Este no es el concepto que manejaban Maquiavelo, ni Shakespeare, ni otros humanistas.

No obstante, ignorando el desarrollo histórico, político y filológico de este término, hay comentadores del siglo XX y XXI quienes alegan que Maquiavelo (siglo XVI) es el primer pensador de hablar del estado en su concepto moderno e impersonal en el sentido marxista. Como veremos, esta determinación no es aconsejable. Sería mejor examinar la palabra, la idea o concepto de "estado" en su contexto. Si no sobreponemos conceptos posteriores y demasiado modernos a ideas y conceptos del siglo XVI, es más posible acercarnos al significado de lo que está diciendo Maquiavelo y los humanistas cívicos del siglo XVI. Esta práctica de sobre posición de ideas modernas en textos renacentistas para así encontrar la lucha de clases, revoluciones y aparatos del estado es una imposición ajena al sentido de un texto y causa errores cuando intentemos entender no 
solamente un texto en su contexto histórico, sino los fenómenos reales e históricas descritos en los textos.

Para comenzar, es hacia Roma que debemos voltear los ojos. Petrarca, para comenzar otra vez, encomendó volver a Cicerón. Y los humanistas cívicos de Florencia a partir de los siglos XV y XVI lo siguieron. Así que, no era en las páginas de Thomas Hobbes ni de Carlos Marx que los humanistas buscaban entender el estado. Durante el quattrocento y cinquecento, los tiempos de Maquiavelo y demás umanisti de Florencia, igual como durante los tiempos de Shakespeare en Londres de los Tudors y Stuarts, escribiendo sus dramas históricos sobre Roma, el concepto del estado prestaba mucho del abogado y cónsul romano, Marco Tulio Cicerón [Don Tully por cariño y familiaridad]. Los italianos, en su afán de siempre ir ad fontes a los griegos y romanos, estudiaban especialmente los romanos, quienes eran sus propios antepasados, para prestar conceptos de gobierno - a tal grado que el contemporáneo más joven de Maquiavelo, Francisco Guicciardini, en su Considerazlione intorno ai Discorso del Machiavelli (1530) se declara harto del constante elogio a la superioridad de los romanos. Un punto más, es que uno de los comentadores modernos mas reconocido sobre estos textos es el Regius Profesor de Historia de la Universidad de Cambridge, Quentin Skinner. Skinner califica a estos pensadores no como humanistas cívicos, sino como neo-romanos. (Véase Visions of Politics, 3 v. (Cambridge, 2002)).

Sin embargo, a la misma vez, no debemos de dudar que Maquiavelo y Shakespeare habían estudiado el pensamiento romano de Cicerón y sus interpretaciones de la política como el arte de fundar, preservar y reformar una res pública que Cicerón presenta en sus obras, De Re Publica y en su De Oficiis. Es el arte dello stato de como una comunidad de ciudadanos libres e iguales viviendo juntos en un régimen de derecho, buscando el bien común por medio de seguir a las cuatro virtudes, pilares de la visión romana de la ética política: la justicia, la prudencia, la fortaleza y la templanza. Estas ideas constituyeron el pan de cada día no solamente en Florencia, sino también en las escuelas y universidades, en el drama y el teatro y en la política de Londres isabelina. (Cicerón mismo aparece como un personaje en la obra Julio César de Shakespeare).

Siguiendo a Cicerón, Tito Livio, Salustio y Tácito, entre otros pensadores romanos, descubrimos que, para la Modernidad Temprano en Europa, cuando se están buscando como distinguir entre un principado y una republica, la forma ideal de un status era, usualmente, la civitas libere, un estado o ciudad libre. Es decir, una republica en que la voluntad de sus cives, y no 
los súbditos, se hicieron sentir sus ideas sobre asuntos públicos. Ideas de este índole se pueden encontrar en los lemas de los umanisti: consideramos que no se tiene que ser de la clase aristocrática para servir a su república: por ejemplo, virtus vera nobilitas est [Virtud real es suficiente para ser noble].

Regresando a la metodología propuesta, la primera premisa sería que no solamente en distintas circunstancias históricas cambian el significado de una palabra y concepto, sino que históricamente las palabras y conceptos políticos dejan de significar lo que originalmente significaban $y$, aunque la palabra queda en forma linguistica igual- $\mathrm{O}$ sea, la ortografía es la misma--el contenido político, muchas veces, asume un significado nuevo después del paso de unos siglos, eventos y escritos de pensadores sobre los asuntos. Tal es el caso con el concepto de virtù [que no es traducible como virtud] y con el concepto del stato, state, l'état, estado, que no es el mismo fenómeno en el siglo XVI que en el siglo XIX en adelante.

En la confección de cualquier argumento prolongado, siempre es aconsejable explicar lo que no se está haciendo en una examinación filológica y política cuando examina un concepto o palabra. Era Tucídides quien examinaba esta idea por primera vez en Occidente. Fue traducido al latín y, posteriormente, por Thomas Hobbes al inglés florido del siglo XVII. De momento, en el siglo XV, Tucídides era conocido, comentado y estudiado por primera vez por los humanistas florentinos y venecianos cuando manuscritos bizantinos de su Historia de la Guerra del Peloponeso, escrito en griego, se llevaron a Italia desde Constantinopla en 1453 después de la Caída de Constantinopla ante los turcos otomanos. Era Tucídides quien toma nota que, bajo presiones políticos en lo extremo, las palabras, declara, irónicamente, tienden a cambiar sus significados. Consideramos su análisis de como cambia el significado del discurso político en estas circunstancias:

Para insertarse bien en los cambios de eventos, las palabras, también, tenían que cambiar sus significados usuales. Lo que fue considerado como un acto insensato de agresión fue ahora considerado el valor y hombría que se debe encontrar en un miembro del partido; pensar en el futuro y esperar fue considerado otra manera de decir que uno era cobarde; cualquier Idea de moderación fue ahora considerado un mero esfuerzo de disfrazar el carácter sin valor; la habilidad de examinar $y$ entender un asunto por todas las ópticas posibles cambió para que indicara que uno fue totalmente no apto para la acción. El entusiasmo fanático llegó a ser el signo de un verdadero hombre y de intrigar contra un contrincante atrás de su 
espalda llegó a ser considerado una auto-defensa perfectamente legitima ... y, en verdad, la mayoría de la gente están más prestos a denominar la cualidad de ser listo como malicia que denominar honestidad inocencia de pensamiento."

[Thucydides. The Peloponnesian War III, 82, traducción del griego al inglés por Rex Warner, Ed. The Penguin Classics, pp. 209-210. Traducción propia.] $]^{2}$

En conclusión a esta clarificación, no estaremos aquí y ahora examinando el concepto del estado así como se ve alterado por las circunstancias cambiantes, oportunistamente -el tema que plantea Tucídides en esta selección de su texto. No, es a los cambios históricos en la formación y metamorfosis de los estados renacentistas reflejadas en los textos por el término estado representando su participación en estos cambios.

La segunda premisa sería que en el siglo XVI, se utilizaba en casi toda Europa, un concepto patrimonial del gobierno. Como explica Quentin Skinner, cuando Maquiavelo habla de lo stato o stati, está hablando de il suo stato: en otras palabras, en el genitivo, refiriendo al estado que pertenecía a alguien. Se podía distinguir, antes del siglo XVII, cosé di stato (asuntos del estado; statecraft) de las personas históricamente encargados de sus estados porque es un concepto pa- trimonial. O sea, para Maquiavelo, Salutati, Bruni, Guicciardini, no hay expresión o entendimiento conceptual del estado como autoridad o aparato distinto y separado de los reyes o príncipes que lo gobernaban. [Véase Visions of Politics, Vol. II, Renaissance Virtues (Cambridge, 2002)]. Siempre es el estado de alguien, que pertenece a alguienya sea los Visconti, los Sforza, etc. o a los ciudadanos junto con un príncipe en una república que no es necesariamente una democracia. (A propósito, sería interesante mencionar que es Guicciardini, en sus Consideraziones sobre los Discursos de Maquiavelo sobre Tito Livio que utiliza por primera vez, el término ragione di stato—razón del estado. Este término no lo utiliza nunca Maquiavelo. Pero este es agua para otra molina.)

Hemos establecido que la forma de preferencia dello stato durante este período de tanta transición, es una república, sombra y reflejo de la República Romana encomendado por Cicerón, el pensador más popular y sobresaliente en casi toda Europa. Recapitulando lo que ya es sabido, en los Discursos sobre la Primera Década de Tito Livio, Maquiavelo, en su ragionare lo stato, se declara en favor de un estado republicano en esta obra. Esta república, por seguro, repito, no es necesariamente una democracia en el sentido que entendemos los términos y fenómenos de república y democracia hoy. Estos términos 
y conceptos en el siglo XVI eran análogos al concepto ciceroniano de una republica, con una constitución mixta.

Talvez es el momento para un desvío para definir un poco el concepto del estado como república utilizado por los humanistas cívicos, prestando, como hicieron, de los pensadores greco-romanos.

República, como forma y concepto de gobierno, fue entendido como una comunidad (civitas) gobernado mas que nada por un elite aristocrático, un elite que se preocupó por el bien común y la vida intelectual. Es decir, el elite no participó en actividades comerciales, ni en asuntos bancarios, si no que vivían de su propiedad (i.e., tierras), actividad que eliminó la necesidad de ser adquisitivo. Conduce, de otro modo, a una vida de virtud cívica. (El debate sobre otio et negotio era central en la vida política renacentista). Para Cicerón y demás, el objetivo máximo de un gobierno era el ejercicio de virtudes públicas y privadas concebida no como la búsqueda solamente del bienestar de la mayoría de la población, pero concebido en la práctica—o sea, por la necesidad práctica en la vida real, como un régimen mixto. Una república, desde los tiempos y escritos de Polibio quien elogió la Constitución de Roma porque era una constitución mixta, combinando aspectos aristocráticos (i.e., el Senado) con algunos aspectos democráticos (i.e., la Tribuna de los Plebeyos). El reto era de combinar asuntos y evitar que la virtud máxima no se vuelve solamente y meramente una modalidad para garantizar la seguridad, alimentación, etc. para la población: que la virtud cívica y privada se conserve también.

Mas temprano todavía, debemos mencionar el esfuerzo de Tomás Moro de introducir un entendimiento, un examen de las ideas clásicas de Cicerón sobre virtudes cívicas en como gobernar un estado en su obra Utopia (1516), contemporáneo con El Cortesano de Castiglione (traducido al inglés por Sir Thomas Hoby) y Los Seis Libros de la República de Jean Bodin, que presenta fascinantes ideas sobre el estado y su soberanía importados desde el otro lado del Canal de la Mancha, también disponible en inglés durante este período en Londres. Todas estas obras tratan ideas del estado en los conceptos y términos prestados siempre de Roma por medio de Cicerón.

Decir que "el estado", en este caso, una república, es un concepto patrimonial, es decir que, antes de Hobbes, no se podía aseverar que el estado, en contraposición a la comunidad sobre la cual ejerce gobernación, constituía la sede de soberanía. Tenemos que repudiar, entonces, la concepción del estado como agente independiente del pueblo y de quien lo gobierno, para 
el siglo XVI en Florencia y Londres, aun cuando encontramos la palabra status [o sus equivalentes en los vernáculos, l'état, state, Staat, stato, estado].

Ahora, hay que establecer la provenance y disponibilidad de este flujo de ideas y pensamientos humanísticos, recogiendo ideas y prácticas de los romanos desde Florencia hacia Londres isabelina, si vamos a poder aseverar que Shakespeare tenía acceso a estas ideas de Cicerón y Maquiavelo. En una tercera premisa, debemos poder establecer que Shakespeare y otros las utilizaba en sus obras dramáticas y poesía. Estamos, por supuesto, hablando siempre y principalmente, de en que consistía el arte dello stato en los textos de Maquiavelo.

La obra de los Discursos aparece impresa en Inglaterra, España y otras partes de Europa. Hay, en Londres, por ejemplo, muchas alusiones a Maquiavelo y sus ideas en obras en prosa y dramatúrgicas isabelinas y jacobinas. Baste con mencionar El judío de Malta y Doctor Faustus de Christopher Marlowe y las varias obras de Shakespeare y de Ben Jonson. Pero más al caso, los Discursos sobre la primera década de Tito Livio de Maquiavelo mismo fue traducido al inglés en 1599 por un tal John Levytt y circulado ampliamente en círculos intelectuales y teatrales, aunque no fue formalmente publicado. Existe en la British Library en forma de Manuscrito 41162.

En estas numerosas traducciones al inglés, durante el período isabelino, de importantes tratados italianos - florentinos y venecianos- sobre el gobierno republicano parecido a la República Romana para tomar solamente un ejemplo, se lee, en una de estas traducciones, de "citizens, by whom the state of the Cittie is maintained" [ciudadanos, por quienes el estado [i.e., lo stato] de la ciudad [i.e., [civitas] es mantenido o preservado y protegido intacta]. Esta obra de traducción por un tal Lewes Lewkenor, publicado en Londres en 1599, es una traducción al Inglés del siglo XVI de la obra veneciana, escrito originalmente en Latín, De Republica Venetorum de Gaspar Contarini. Examinando la terminología que maneja Contarini y Lewkenor, sobre el estado, corremos el riesgo de cometer un error histórico, político y filológico si nos proponemos entender, desde este texto, una separación o distinción entre ciudadanos y el estado de su ciudad (léase civitatis, en latín, que, en este mismo texto Lewkenor también utiliza, traduciéndo la res publica del Latín de Contarini, como republic o state en su texto inglés con el afán de elevar el prestigio de la Ciudad de Londres con presentarla en los mismos términos que una república romana.

Enfocándonos, por lo tanto, en el término estado ahora en el siglo 
$\mathrm{XVI}$, lo stato de Maquiavelo ha llegado a Londres y es utilizado en la misma modalidad en que lo utiliza Maquiavelo, es decir: lo suo stato, aunque, para estar claro, en la traducción al Inglés de Contarini por Lewkenor, y en muchos textos mas en Londres y Florencia, se contraste la libertad de regimenes republicanos con el servidumbre que es sine qua non de gobiernos monárquicas. En Contarini, Lewkenor, et al., no se percibe el estado como una autoridad del gobernador distinta de los ciudadanos. Esta visión está en contraposición a lo que se puede imaginar como la percepción de una autoridad o aparato impersonal del gobierno (léase, príncipe) tipo Hobbes. En Contarini y Lewkenor, "the state of the Cittie" es inherente en el cuerpo o masa de ciudadanos, pertenece a ellos pero no es ellos. Es una república [palabra que Lewkenor traduce como "the state of the Cittie"]. El estadociudad-república pertenece a los ciudadanos quienes mantienen $y$ preservan "the state of the Cittie", en una manera patrimonial, casi en el caso genitivo, pero ellos no conforman el estado-ciudad-república se consideraron como Troy Novaunt [término en Anglo-Normand que significa que Londres era la Nueva
Troya] en efecto, troyanos, porque alegaron, para alimentar su prestigio como civitas, que su ciudad fue fundado por Eneas, en su translatio imperii después de la Guerra de Troya. Grecia y Roma vivían en los aires de Londres isabelino, en contraposición del Londres de los comerciantes que traía mucho dinero pero que apestaban de las muelles.

Tomemos nota de que el año 1599 —en que Lewkenor y Levytt estaban haciendo sus traducciones- es el mismo año en que $\mathrm{Wi}$ Iliam Shakespeare produce su obra dramática Julio César en el escenario del Globe Theatre en Londres. Así que, aquí podemos comparar el uso por Shakespeare de la palabra state, en el mismo sentido que Maquiavelo, con la manera en que Lewkenor lo traduce en el tratado sobre la republica de Contarini, el veneciano, para repetir, publicado en 1599.

Bruto, en Julio César, presenta la turbulencia del pueblo romano a la audiencia del teatro en Londres/ Roma en la siguiente manera, aplicando y efectuando una conflación del concepto del estado con el estado psicológico de Bruto, como hombre individual, actuando en la misma manera que una república:

Since Cassius first did whet me against Caesar

I have not slept.

Between the acting of a dreadful thing

And the first motion, all the interim is

Like a phantasma or a hideous dream.

The genius and the mortal instruments 
Are then in council, and the state of man,

Like to a little kingdom, suffers then

The nature of an insurrection"

[II.i.61-69]

[Desde que Casio me estimuló contra César

No he dormido.

Entre la actuación del asunto de terror

Y la primera moción, todo el tiempo interino es

Como una fantasma o un sueño horrible.

El genio y los instrumentos mortales

Están, entonces, en reunión de concilio,

y el estado del hombre, parecido a

un reino pequeño, sufre, entonces,

la naturaleza de una insurrección.] [Traducción propia]

Shakespeare utiliza una comparación y conflación, a la vez del hombre individual con el "state" [i.e., status, stato, estado] como un pequeño reino que sufre un disturbio, una insurrección en los pensamientos y estados psicológicos precarios de Bruto, considerando su participación en el asesinato de César. En eso, Bruto es un hombre ragionare lo stato. Es la lucha por el control de un alma que consiste, metafóricamente, en un estado: la vida interior, el alma, de Bruto, se convierte en un estado, y, más específicamente, en una república con su concilio reunido. Obviamente, este no es una lucha de clases contra un aparato impersonal de un estado por una clase conciente de sus intereses. Es una metáfora orgánica en que el estado no es separado ni separable del ciudadano individual y su funcionamiento interno y psicológico.
Aunque muchos críticos literarios y políticos utilizan la misma palabra en sus analices de estos textos shakespeareanos - estadoes profundamente anacrónico imponer el concepto del estado que utilizamos hoy, por ejemplo, sobreponiendo conceptos del estado extraídos de los escritos de Marx, Gramsci, Poulantzas, Althusser, y demás pensadores marxistas, indican precisamente el estado moderno. El argumento es que, en las obras romanas de Shakespeare, este no es el caso.

Esta imposición de conceptos modernos de estado en textos renacentistas llevan consigo muchas implicaciones para el entendimiento del texto y lo que está diciendo de como funcionaban los asuntos "estatales". Pero el error es más profundo. El estado que contemplamos hoy, no es de las mismas 
dimensiones que el estado en textos renacentistas-en el mundo político y geográfico de Europa de los siglos bajo consideración. Lo stato en Maquiavelo y the state en Shakespeare no son el estado moderno de hoy $y$, por lo tanto, no podemos extrapolar luchas de clase ni en los textos de Maquiavelo ni en los de Shakespeare.

Examinemos esta aseveración un poco más de cerca con referencia a una de las obras más políticamente analítica de Shakespeare. En Coriolanus, por ejemplo, hay disturbios entre la población pidiendo pan y para la expulsión de un general, candidato para el puesto de Cónsul, quien desprecia las tribunas de los plebeyos (este es Coriolano mismo). Estas actividades simplemente no se pueden cualificarlos como luchas de clases, definidas como actuaciones de una clase organizada, conciente de sus propios propósitos y luchando por si mismo en el sentido moderno. Las actuaciones que nos presenta Shakespeare en sus obras romanas son más parecidas a un jacquerie o disturbio, una alteración temporal del status quo político. A lo máximo lo podemos calificar como una rebelión limitada —ni llegan a ser calificadas como una insurrección organizada. Para Shakespeare, estos personajes forman partes del cuerpo orgánico, el estado concebido como un cuerpo humano (el estómago, por ejemplo, en su metáfora del primer acto de Coriolanos) de que estas personas son dueños patrimoniales. De hecho, el estómago (léase plebeyos), es, en el metáfora del estado presentada, parte del organismo humano del estado.

Ahora, calificar estos fenómenos representados en las obras romanas de Shakespeare como luchas de clase no es solamente un problema de traducción y filología, sino un problema de la falsa representación de una realidad sobrepuesta desde el siglo XXI.

Pensamos, para aclarar, en un ejemplo explicativo y más familiar: la práctica de traducir la palabra virtù de un texto florentino o veneciano-el ejemplo más reconocido. En los textos de Maquiavelo y de otros pensadores de las repúblicas de la Península Itálica durante el quattrocento, usualmente traducen la palabra virtù con la palabra virtud. No es su equivalente. Pero un sinnúmero de textos modernos de Maquiavelo y otros salen de la imprenta hoy en día con exactamente esta palabra como traducción.

Virtù simplemente no es virtud y no captura el sentido del texto ni del pensamiento. Pero más, este es el caso porque virtù no es solamente una palabra, sino un concepto de su tiempo que describe un actitud, acciones y modos de ser y manera de ver las cosas características del ambiente de Maquiavelo, Guicciardini, Castiglione, Salutati, Bruni y 
muchos más. El asunto es que el concepto de virtú no existe como parte del vocabulario ni el modo de ser política ni filosóficamente hoy; no es parte del Weltanshauung del siglo XXI. En fin, utilizar la palabra virtud como equivalente de virtù es tergiversar el significado del texto y pensamiento fuera de todo reconocimiento. He mencionado este ejemplo para ilustrar, en forma paralela, por medio de una comparación parecida a lo de la problemática del estado, que lo mismo es el caso con la palabra y concepto del estado. Aunque la palabra es igual, el significado ha cambiado desde el siglo XVI.

Hemos establecido que los pensadores en Florencia, Paris y Londres, no utilizaron la palabra estado, state, l'état, stato con el mismo significado que hoy utilizamos la palabra estado o state. No obstante, se puede leer en libro tras libro que Maquiavelo es el primer escritor que utiliza el concepto del estado moderno en sus escritos del siglo XVI. Palabras y conceptos como virtud o estado no son virtù o stato. Enfin, el jugo de remolacha no es sangre, aunque se parece.

Reflexionando sobre la historia, gobierno e instituciones, y específicamente el estado republicano de Roma, era un ejercicio obvio y de riguer para muchos pensadores de la península italiana, comenzando con Petrarca y pasando por cada uno de los umanisti de Florencia desde Dante y Petrarca, Coluccio Salutati, Leonardo Bruni y Francesco Guicciardini hasta llegar a Nicolás Maquiavelo, para mencionar solamente los más famosos. Pero hay docenas de pensadores, estadistas, diplomáticos, reyes, príncipes laicos y eclesiales, condottiere, gonfaloniere, priores y otros tipos de gobernadores que estudiaban, argumentaban y escribieron sobre la historia del estado republicanos de sus antepasados en Roma: es decir, ragionare el arte dello stato. Estos pensadores y filósofos del siglo XVI utilizaron la palabra stato cuando examinaron las dimensiones de este fenómeno del estado republicano extraído del pasado nacional de Roma, pasando por los descendientes romanos de Florencia, Venecia, Padua, Bologna, et al.

Roma, entonces, era el faro histórico para quienes estudiaron estos artefactos políticos, las nuevas formas de gobierno durante las horrendas Guerras de Religión en Europa. El estado más idóneo que proponían, como hemos visto, siguiendo Cicerón, era una republica, y la república más idónea era la republica romana que describe Cicerón y Tito Livio. Maquiavelo ragionare lo stato de Florencia por medio no solamente de Cicerón sino, principalmente por medio de la prisma de Tito Livio y sus historias romanas. Roma era el faro.

Shakespeare examinó Roma y el desarrollo histórico de su estado 
en no menos de seis obras: The Rape of Lucrece (1593), Coriolanus (1608), Julius Caesar (1599), Antony and Cleopatra (1606), Titus Andronicus (1589-92) y (1608-10). La situación y ubicación geográfica interna de estas obras es Roma, desde su fundación pasando por la monarquía, la república y el imperio hasta el retiro de las Legiones Romanas de Britania en el siglo IV y el comienzo del cristianismo en la isla. Pero, toma nota, que el lugar físico en que se lleva acabo el accionar de cada uno de estas obras romanas de Shakespeare, presentadas en Londres, es Italia.

Su primera obra sobre Roma es el poema The Rape of Lucrece (1593), Shakespeare dibuja la violación de Lucrece por el rey tirano, Tarquino, y la subsiguiente expulsión de los Tarquinos que siempre implicaba el fin de la monarquíatiranía y los comienzos de la Republica Romana.

Coriolanus, presentado en Londres en 1608, presenta el segmento de la historia de Roma que sigue con el establecimiento de la tribuna de los plebeyas en 494 B.C.E. e incluye los disturbios contra el nuevamente establecido gobierno y los procesos de las campañas electorales de los romanos y la elección de los oficiales romanos: consules, tribunas, censores y aediles. La obra-muy moderna en sus temas-presenta una insurrección de ex-combatientes quienes no han recibido su comida ni pensión ante el trasfondo de políticos del Senado de los partidos antiguos de aristócratas que están acaparando los granos básicos. La obra, en cierto sentido, presenta el establecimiento de los principios de una república en la formación de los puestos de Tribunas del Pueblo, pero no presenta la transferencia del poder al pueblo desde el Senado [SPQR], ni a los individuos, sino a las tribus. [Véase "El Estado renacentista: Una obra de ate en Shakespeare". www. uca.edu.sv.]

Julio César, presentado en el Globe Theatre en Londres en 1599, presenta lo que sigue con la historia romana: el asesinato de Julio César y la Batalla de Philippi (42 B.C.E.), presentando los tiempos del fin de la Republica Romana y el comienzo del Imperio Romano bajo Octavio (César Augustus).

Antony and Cleopatra, presentado en 1606, continúa con la historia de Roma desde escenarios en Alejandría, Roma, Sicilia, Actium y Atenas, y sigue hasta el surgimiento y caída del Segundo Triumvirato e incluye la famosa Batalla de Actium de 31 B.C.E. y la muerte de Marco Antonio y Cleopatra.

Titus Andronicus (1589) presenta las batallas de los romanos contra los Godos y presenta la disolución del Imperio Romano comenzando en el siglo IV A.D. cuando se retiraron las Legiones de Roma de la Isla. 
Finalmente, Cymbeline (1608) presenta el conflicto entre Roma Antigua y la Britania moderna durante el reino de Augusto, igual como el movimiento hacia Occidente del Imperio (traslatio imperii) y el dominio eventual del mundo cristiano en Inglaterra.

Shakespeare examinó la historia y el desarrollo de la República Romana utilizando la palabra estado como fue utilizado en la ciudad de Londres durante los tiempos isabelinos y jacobinos finales del siglo XVI y principios del siglo XVII, ya sea el estado de Tarquino, o de Julio César, o de los tiempos de Julio César cuando Cicerón era Cónsul de la República, o del Imperio Romano de César Augusto.

Se debe mencionar que la visión de Shakespeare acerca de Roma, y presentada en estas obras, la tomó en gran parte de una traducción al inglés de las obras en griego de Plutarco, y del romano Virgilio. Las vidas paralelas de los Ilustres griegos y romanos de Plutarco fueron traducidas para los londinenses en 1579 por Sir Thomas North y estudiado en las escuelas y universidades de esta ciudad; igual como La Eneida de Virgilio traducida al italiano en 1419 por Pier Candido Decembrio, un milanés, y del italiano al inglés para publicación en Londres en 1584.

Cada una de las cinco obras dramáticas y el poema sobre Lucrecia de Shakespeare revela y presenta a su audiencia, desde la escena teatral, la historia de Roma para la población entera de Londres. En la misma manera que la ontología recapitula la filogenía en la ciencia de biología, las obras romanas de Shakespeare reproducen una recapitulación desde la escena del Globe en Londres, de la historia del estado romana muy influenciado por los umanisti florentinos, que Shakespeare, obviamente, pensaba que era parecida $y$, por lo tanto, ilustrativa como lecciones morales y éticas, para su mundo en Londres, tan Ileno de la violencia y sangre de la venganza.

Somos testigos, en Maquiavelo y en Shakespeare, en Florencia y Londres, de una transformación enorme pero exquisita del estado, lo stato. La persona puesta en el corazón del estado, entonces, no es el aparato artificial del estado moderno. Todavía es la persona individual en todas sus dimensiones políticas y psicológicas.

Todas estas seis obras de Shakespeare se llevan acabo en Roma, una Roma trasladada a Londres por medio de influencias literarias, intelectuales y políticas de los humanistas florentinos. Estamos siempre en Londres pero estamos en Roma en Florencia y Roma en Londres y en toda la Cristiandad de la Europa Occidental del siglo XVI, presenciando, observando y considerando, en la escena del Globe Theatre, el arte dello stato. 
Lecturas recomendadas:

Anglo, Sydney. Machavelli. The First Century. (Oxford-Warburg Studies, 2005)

Finer, Samuel E. The History of Government from the Earliest Times, 3 v. (Oxford University Press, 1998)

Machiavelli, Niccolò. Opere. A cura di Corrado Vivanti (Torino: Einaudi-Gallimard, 1997)

Maquiavelo, Nicolás. Epistolario, 1512-1527 (México: Fondo de Cultura Económica, 1990)

Notas

1 "Pure, se io vi potessi parlare, non potre' fare che io non vi empiessi il capo di castellucci, perché la fortuna ha fatto che, non sapendo ragionare né dell'arte della seta e dell'arte della lana, né de'guadagni né delle perdite, e'mi conviene ragionare dello stato, e mi bisogna o botarmi di stare cheto, o ragionare di questo." [Lettere 367 en Opere di Niccolo Machiavelli, iii, ed., Franco Gaeta (Turin, 1984)

2 "To fit in with the change of events, words, too, had to change their usual meanings. What used to be described as a thoughtless act of aggression was now regarded as
Shakespeare, William. Teatro completo, Ed. Jaume Plensa; Traductor, Ángel-Luis Pujante (Barcelona: Galaxia Gutenberg, Círculo de Lectores, 2006

Shakespeare, William. The Norton Shakespeare, based on the Oxford Edition. Ed. Stephen Greenblatt

Skinner, Quentin. Visions of Politics. 3 v. (Cambridge University Press, 2002)

the courage one would expect to find in a party member; to think of the future and wait was merely another way of saying one was a coward; any idea of moderation was just an attempt to disguise one's unmanly character; ability to understand a question from all sides meant that one was totally unfitted for action. Fanatical enthusiasm was the mark of a real man, and to plot against an enemy behind his back was perfectly legitimate selfdefense ... and indeed most people are more ready to call villainy cleverness than simple-mindedness honesty. They are proud of the first quality and ashamed of the second." Thucydides. The Peloponnesian War III, 82, Op. Cit. 